\title{
Las influencias políticas y sociales en el ejercicio de la autoridad en la cárcel
}

\author{
Ignacio González Sánchez
}

Universitat de Girona

nacho.gonzalez.sanchez@gmail.com

Recepción: 02-11-2018

Aceptación: 08-03-2019

Publicación: 29-04-2019

\section{Resumen}

Este texto pertenece a una mesa redonda que ofrece un debate con James B. Jacobs, autor del clásico de la sociología de las prisiones Stateville: The penitentiary in mass society, sobre la vigencia de su obra cuarenta años después. Este comentario destaca dos contribuciones importantes de la obra y las relaciona con cambios acaecidos en la sociedad y en la articulación del castigo desde entonces. En primer lugar, y a partir de este ejemplar estudio de las relaciones entre la cárcel y la sociedad, se plantea si esta ha variado sustancialmente con la existencia de mayores canales de comunicación y con el incremento de personas encarceladas. En segundo lugar, reconociendo su excelente uso de Weber para entender el castigo, se plantean dinámicas contradictorias que empujan a la vez hacia un ejercicio de la autoridad más legal-racional y más carismático.

Palabras clave: encarcelamiento de masas; sociología de la cárcel; Weber; gerencialismo; populismo penal

Abstract. Social and political influences on the exercise of authority in prison

This text belongs to a round table which offers a discussion with James B. Jacobs, author of the classic in sociology of prisons Stateville: The penitentiary in mass society, on the importance of his work 40 years later. This commentary stresses two important contributions of his work and relates them to changes in society and the configuration of punishment since then. First, this outstanding study of the relations between prison and society is used as a springboard from which to pose the question of whether this relationship has varied substantially with the existence of more channels of communication and the increase of people being imprisoned. Second, acknowledging his excellent use of Weber for understanding punishment, the issue of contradictory dynamics pushing for a more legal-rational and more charismatic exercises of authority is raised.

Keywords: mass imprisonment; sociology of prison; Weber; managerialism; penal populism 


\section{Sumario \\ 1. La relación cárcel-sociedad Referencias bibliográficas}

2. La autoridad y el estudio del castigo

El libro Stateville: the penitentiary in mass society, de James Jacobs, es una obra que ha pasado en estas cuatro décadas de ser un gran libro a ser un clásico de la sociología de las prisiones. El libro es sobresaliente, no tanto por su trabajo empírico, de enorme valor (es de especial interés el apéndice metodológico del libro), sino por las posibilidades que abre para pensar mejor (o, al menos, más sociológicamente) tanto las cárceles como el funcionamiento del castigo. En este sentido, sus aportaciones a la sociología de las cárceles giran en torno a mostrar que, a pesar de los muros y la opacidad político-administrativa, las cárceles son sitios permeables a las influencias de la sociedad, y muestra, para su estudio de caso, cómo. Para la sociología del castigo, su trabajo es uno de los muy pocos que han puesto en funcionamiento las ideas de Max Weber para comprender mejor la forma en que se ejecutan los castigos, concretamente el ejercicio de la autoridad dentro de la cárcel y que, si se tiene en cuenta el punto anterior, se relaciona con el de fuera.

Este comentario no se centra en criticar el contenido del libro, sino en reconocer el efecto estimulante que tiene y cómo su lectura plantea cuestiones sobre varios procesos contemporáneos. En este sentido, primero nos centraremos en cómo puede haber afectado el desarrollo de los medios de comunicación y el encarcelamiento de masas en la porosidad de esta institución de encierro; $y$, segundo, también en la influencia que han podido tener en las formas de autoridad penitenciaria dos dinámicas contradictorias: el populismo penal y el impulso de las macrocárceles.

\section{La relación cárcel-sociedad}

Stateville continúa explícitamente la línea de estudios sociológicos de la cárcel iniciados por Donald Clemmer (1940) y asentados con Gresham Sykes (1958), cuyo eje básico es entender la cárcel como un espacio que no está aislado. Es decir, entender la cárcel como un espacio relacional, tanto entre las personas que viven o trabajan en ella como entre la propia institución y otras instituciones y dinámicas organizacionales (el mercado laboral o el sistema electoral, por ejemplo). La sociedad de masas a la que se refiere el autor en el subtítulo del libro se estaba desarrollando mucho a principios de los años setenta, pero actualmente hay algunos aspectos ya plenamente desarrollados que son considerablemente diferentes con respecto a la época en la que Stateville fue escrito. En concreto, los canales - y los medios- de comunicación (en principio transformados por la llegada de los televisores a las casas, después por los teléfonos móviles y ahora por Internet). El otro aspecto — más netamente relacionado con la temática del libro- tiene que 
ver con lo que se ha llamado mass imprisonment (y que aquí traduciremos como encarcelamiento de masas, frente a la traducción más habitual de encarcelamiento masivo).

En Stateville se sugiere que cuantos más canales de comunicación existan entre la sociedad y los presos, mayor será la influencia del exterior en el mundo carcelario (Jacobs, 1977a). La presencia hoy en día de periódicos en prisión, cuando no se está en régimen de aislamiento, es habitual, así como también una gradual y persistente mayor presencia de televisores en las celdas (si no, al menos, en la sala común del módulo). Además, el acceso a llamadas telefónicas, si bien siguen siendo injustificablemente más caras que en la calle — donde, además, no se da la situación monopolística que defiende la SGIP con empresas como Telefónica, Santander o El Corte Inglés y uno puede elegir-, es una práctica extendida y muchas veces el principal problema es no tener con quién hablar. Caso aparte es la presencia de teléfonos móviles en prisión (no contemplada legalmente), que permite hasta enviar y recibir vídeos y fotos al instante. Es decir, es más fácil que exista comunicación (bidireccional aunque asimétrica, pues la posibilidad de hacer llegar mensajes desde dentro de la prisión al exterior es mucho más difícil).

Por otro lado, la explosión de la práctica del encierro carcelario ha revitalizado uno de los debates clásicos en los estudios sociales sobre la cárcel: la existencia de una cultura específicamente carcelaria (Crewe, 2008). Como es sabido, el debate oscila entre interpretaciones más funcionalistas, que explican los comportamientos y valores de los presos como un mecanismo adaptativo generado dentro de la cárcel como respuesta a las privaciones del encarcelamiento (ya sean físicas, emocionales, identitarias o materiales) (Sykes, 1958; Goffman, 1961), hasta tesis que cuestionan la mortificación del yo y el origen carcelario de estos valores y que señalan que las personas que ingresan en prisión lo hacen también con sus valores, que no se quedan en la puerta de la cárcel. Así, la cultura carcelaria sería una adaptación de los valores culturales de los grupos más encarcelados (generalmente de clases populares, minorías étnicas y habitantes de barrios estigmatizados) (Irwin y Cressey, 1962). También se ha señalado que se produce una exportación de los valores culturales de la cárcel hacia la calle y que, especialmente en el gueto estadounidense, se está produciendo una mezcla de las dos culturas. Desde este punto de vista, el encarcelamiento de masas ha supuesto un mayor flujo de gente que pasa por prisión, que importa valores de la calle y exporta valores carcelarios (independientemente de que las penas ahora sean bastante más largas que hace cuatro décadas) (Wacquant, 2001).

Más allá del debate sobre el contenido y las características de la cultura carcelaria (o sobre su misma existencia), parece haber indicios suficientes de que existe cierta relación entre los valores de la cárcel y los del resto de la sociedad. La duda era si, teniendo en cuenta estos dos aspectos (más canales de comunicación y más personas entrando y saliendo), se podría pensar que la relación cárcel-sociedad (que, como todas las relaciones, son variables) es ahora más intensa que en los años setenta, a pesar de que más gente pasando por la cárcel 
no necesariamente significa más heterogeneidad, pero sí un mayor flujo ${ }^{1}$. En tal caso, la duda era si el encarcelamiento de masas hace de la cárcel una institución en la que factores y dinámicas extrapenitenciarios deberían tenerse cada vez más en cuenta en los estudios sobre prisiones y encarcelamiento.

\section{La autoridad y el estudio del castigo}

Siguiendo con esta aproximación, es lógico pensar que, si las formas de ejercer la autoridad han cambiado fuera, también lo han podido hacer dentro. A ello le dedica Jacobs buena parte del libro. Según explica, su objetivo era dar cuenta de la transición de un régimen feudal a uno racional-burocrático, y para ello traza la evolución de una autoridad carismática a una tradicional, a una legal-racional (Jacobs, 2018). En esto desempeña un papel fundamental precisamente la apertura de la institución penitenciaria, que cuando el autor la estudió estaba en un proceso en el que formas tradicionales del ejercicio de la autoridad en la cárcel, y que incluían mucha arbitrariedad, estaban dando paso a una organización más democrática, donde se podía pedir rendición de cuentas, al menos en términos legales; un mayor control judicial de la ejecución de la pena; y la influencia de los movimientos por los derechos de las personas presas (Irwin, 1980; Lorenzo, 2013 para un proceso similar en la transición española, con el movimiento de la COPEL, el apoyo desde fuera de la prisión y la elaboración de la ley penitenciaria postfranquista).

Uno de los valores de este libro, a nuestro entender poco reconocidos y aprovechados aún, es el uso del marco teórico de Weber para comprender mejor estos cambios². No es que Jacobs se limite a ese enfoque - también usa a Rusche y Kirchheimer para su conceptualización de las cárceles (Jacobs, 1977b) —, pero sí que es posiblemente quien ha hecho un uso más sistemático de este y con un trabajo empírico muy sólido ${ }^{3}$. Además, el esfuerzo que hace por vincular las formas de autoridad con cambios amplios en la sociedad estadounidense permite una lectura de la reforma carcelaria que no depende de los reformistas, permite reconstituir la cárcel plenamente como una institución social y política que se rige por dinámicas políticas vigentes fuera de la cárcel y,

1. Aquí se encierra un debate que alcanza hasta lo conceptual, pues la cultura de masas siempre ha estado asociada a un producto fundamentalmente para las clases medias, mientras que el mass imprisonment afecta, fundamentalmente, a las clases bajas. A pesar de que en la formulación más sistemática del concepto se reconoce los sesgos habituales del castigo (Garland, 2001a), hay autores que han optado por abandonar el uso de este concepto porque corre el riesgo de invisibilizar el carácter discriminatorio de la reconfiguración del encierro en las últimas décadas (Wacquant, 2008, quien se decanta por usar hiperencarcelamiento).

2. Se nos escapan las razones por las que este trabajo no ha tenido una repercusión aún mayor en la sociología del castigo, que ha desarrollado muy ampliamente la corriente foucaultiana, lleva una década retomando la tradición marxista y guarda un respeto sagrado a Durkheim (lo que incluye venerarlo pero sin atreverse a tocarlo mucho) (Garland, 1990 para las distintas corrientes teóricas).

3. De los pocos trabajos que se podrían llamar weberianos, el más reconocido es el de Savelsberg, 1994. 
por lo tanto, permite estudiar mejor cómo se entienden, practican y respetan las formas de autoridad en el interior.

El período que cubre Stateville coincide con uno al que la literatura suele representar regido por el principio de la rehabilitación (Garland, 2001b: 27-51). Precisamente desde los años setenta, un conjunto heterogéneo de principios coexisten en la forma en que se castiga, por lo que probablemente sería mejor hablar de políticas criminales antes que de una política criminal, así como de políticas penitenciarias, en plural, pues coexisten varias, dependiendo del tipo de delito y de delincuente, al igual que sucede fuera (ni se trata igual ni se busca lo mismo con una persona condenada por terrorismo, por corrupción o por robo a mano armada). En este sentido, dos tendencias que han ganado mucho terreno en las últimas décadas han sido el populismo penal y la construcción de macrocárceles. En el paso a un ejercicio de autoridad legal-racional como el que narra Stateville, la duda era cómo funciona y qué ejercicio de autoridad promueve la interacción entre, al menos, dos tendencias contradictorias (Brandariz, 2016: 68-74). Sería interesante ver qué tensiones crea y cómo se resuelven (o gestionan).

La construcción de macrocárceles tiene como objetivo minimizar los costes económicos por cada persona encerrada. Así, se pasa de centros más pequeños, a veces incluso en núcleos urbanos, donde un trato personalizado, para bien y para mal, es posible, a macrocentros más pensados para el gasto eficiente (¿para quién?) de recursos, con la idea de reducir el gasto en personal en el centro, dispensando un trato más estandarizado, más homogéneo. La gestión automatizada que fomentan estos centros orienta el ejercicio de la autoridad hacia una más racional, con un mayor peso de la burocracia en el gobierno de la prisión (en una dinámica más amplia asociada al gerencialismo). Las condiciones de vida de estas nuevas cárceles han provocado llamadas de atención del Comité Europeo para la Prevención de la Tortura, pues considera que las dinámicas que introducen este tipo de centros son deshumanizantes y contraproducentes para el proceso resocializador (más allá del perjuicio para los familiares, que ven cómo cada vez tienen que desplazarse más para visitar a sus familiares - y que problematiza también lo planteado anteriormente sobre mayores posibilidades de comunicación con el exterior-).

Por otro lado, el populismo penal empuja hacia otras formas de castigar que la literatura tiende a calificar de no racionales, sobre todo por asociarlas a una mayor influencia de las emociones y de algunas demandas populares en la configuración de la política criminal (Sozzo, 2017), y que fomentan formas de autoridad menos previsibles y más caprichosas que dan lugar a una mayor introducción de contradicciones en el ejercicio del castigo y la autoridad. Así, la concesión de permisos puede depender de qué noticia cope los programas matinales y genere alarma social; el acceder a un derecho básico como el de la información depende de que la SGIP decida tomar la medida simbólica de retirar los televisores para dar una imagen de austeridad, así como de cerrar las piscinas (a pesar de que los televisores ya estaban comprados y los técnicos avisaron del alto costo de cerrar las piscinas y después reactivarlas). En siste- 
mas como el estadounidense, en que incluso algunos cargos para dirigir las cárceles locales (jails) son electos, se deja el contenido de la pena de cárcel a los resultados de la competitividad electoralista, con lo que se promueve algunas propuestas muy personalistas que, de hecho, luego justifican medidas que no acaban de encajar mucho con los procesos de formalización y burocratización estudiados por Weber.

En este sentido, y centrándonos en las contradicciones de distintas dinámicas que atraviesan la sociedad, la política criminal y la cárcel, se recuerda que la evolución de las formas de autoridad presentadas por Jacobs (tradicional, carismática, legal-racional) no es necesaria, ni automática, ni lineal, sino histórica y políticamente contingente. Como tal, hay que prevenirse de dar por hecho que la evolución de la vida penitenciaria va hacia formas más racionales y menos arbitrarias. Este libro muestra una forma magistral de estudiarla: con una etnografía y un análisis histórico informado por un buen marco teórico.

\section{Referencias bibliográficas}

BRANDARIZ, José Ángel (2016). El modelo gerencial-actuarial de penalidad. Eficiencia, riesgo y sistema penal. Madrid: Dykinson.

Clemmer, Donald (1940). The prison community. Nueva York: Holt, Rinehart and Winston.

CREWE, Ben (2007). «The sociology of imprisonment». En: Yvonne Jewkes (ed.). Handbook on prisons. Cullompton: Willan.

Garland, David (1990). Punishment and modern society: a study in social theory. Oxford: Oxford University Press.

<https://doi.org/10.7208/chicago/9780226922508.001.0001>

- (2001a). "The meaning of mass imprisonment». En: David Garland (ed.). Mass imprisonment: social causes and consequences. Londres: Sage.

- (2001b). The culture of control. Crime and social order in contemporary society. Oxford: Oxford University Press. <https://doi.org/10.4135/9781446221228.n1>

GOFFMAN, Erving (1961). Asylums. Essays on the social situation of mental patients and other inmates. Nueva York: Doubleday.

IRWIN, John (1980). Prisons in turmoil. Boston: Little, Brown \& Company.

IRWIN, John y CRESSEY, Donald (1962). «Thieves, convicts and the inmate culture». Social Problems 10, 142-55. <https://doi.org/10.2307/799047>

JACOBS, James (1977a). Stateville: the penitentiary in mass society. Chicago y Londres: University of Chicago Press.

- (1977b). «Macrosociology and imprisonment». En: David Greenberg (ed.). Corrections and punishment. Londres: Sage.

- (2018). «Author meets critics: Stateville revisited», III Conferencia Internacional del Master de Criminología y Ejecución Penal. Barcelona, 11 de mayo.

Lorenzo, César (2013). Cárceles en llamas. El movimiento de presos sociales en la transición. Barcelona: Virus.

SAVELSBERG, Joachim (1994). «Knowledge, domination and criminal punishment». American Journal of Sociology 90 (4), 911-43.

<https://doi.org/10.1086/230367> 
Sozzo, Máximo (2017). «Populismo penal. Historia, balance, dilemas y perspectivas de un concepto». Nova Criminis 14, 79-129.

SYKES, Gresham (1958). The society of captives: A study of a maximum security prison. Princeton: Princeton University Press.

WACQUANT, Loïc (2001). «Deadly simbiosis: when ghetto and prison meet and mesh». En: David Garland (ed.). Mass imprisonment: social causes and consequences. Londres: Sage. <https://doi.org/10.4135/9781446221228.n8>

- (2008). «Racial stigma in the making of America's punitive state». En: Mary Louise Frampton, et al. (eds.). After the war on crime: race, democracy, and a new reconstruction. Nueva York y Londres: New York University Press. 
